\title{
The effect of caffeine gum on the performance of recreational runners taking part in parkruns
}

\author{
A. Lynn ${ }^{1}$, C. Rodgers ${ }^{2}$ and M. Ranchordas ${ }^{2}$ \\ ${ }^{1}$ Food and Nutrition Group, Sheffield Business School, Sheffield Hallam University S1 $1 \mathrm{WB}$ and ${ }^{2}$ Academy of Sport \\ and Physical Activity, Sheffield Hallam University S10 2BP
}

Laboratory-based studies have clearly established that caffeine supplementation has ergogenic effects ${ }^{(1)}$, but it is unclear to what extent these effects translate to the field setting ${ }^{(2)}$. We conducted a series of cross-over studies to establish the effect of caffeine gum on the performance of recreationally trained runners taking part in parkruns. Parkruns are free to enter, timed, $5 \mathrm{~km}$ running events held in numerous parks around the UK every Saturday morning ${ }^{(3)}$.

A total of 36 recreationally trained runners $(\mathrm{M}=31, \mathrm{~F}=5)$ capable of running $5 \mathrm{~km}$ in $<25$ min were recruited to 3 studies taking place at Sheffield Hallam parkrun. For each study, 6 runners were allocated into a randomised, placebo-controlled, cross-over intervention with caffeine gum as the active treatment ( $300 \mathrm{mg}$; Military energy gum, Marketright Inc., USA) and 6 were allocated into a non-intervention group. The purpose of the non-intervention group was to adjust for the effect of variable weather conditions on performance. Runners in the randomised cross-over interventions chewed caffeine gum or placebo gum for 5 min, starting 30 minute before each $5 \mathrm{~km}$ parkrun. Finishing time and ratings of perceived exertion (RPE) were recorded. A primary statistical analysis used the data from the cross-over interventions alone. The effect of caffeinated gum on performance and RPE were analysed using paired samples t-tests. A secondary statistical analysis used the non-intervention group data in an attempt to adjust for effect of changing weather conditions on performance times. The times of each runner in the 3 cross-over interventions were divided by the mean time of the associated group of non-intervention runners to produce a ratio. The ratio data was then analysed using a paired samples t-test. The study was approved by the Ethics Committee of Sheffield Business School, Sheffield Hallam University and the Research Review Board of parkrun.

Of the 36 runners recruited to the 3 studies, 29 completed both runs (14 intervention runners and 15 non-intervention runners). The primary statistical analysis revealed that caffeine gum improved $5 \mathrm{~km}$ parkrun performance by a mean of $17.28 \mathrm{~s}(95 \% \mathrm{CI} 4 \cdot 19,30 \cdot 37$; $P=0.014)$ and decreased RPE by $1.21(95 \%$ CI $0.30,2 \cdot 13 ; P=0.013)$. Adjusting the finishing time data using the mean times of the non-intervention groups attenuated the statistical significance $(P=0.037)$.

In conclusion, caffeine gum evokes a modest improvement in $5 \mathrm{~km}$ running performance in recreational runners taking part in parkrun events. Moreover, the improved performance is accompanied by a reduction in RPE.

1. Ganio MS, Klau JF, Casa DJ et al. (2009) J Strength Cond Res 23, 315-324.

2. Burke LM (2008) Appl Physiol Nutr Metab 33, 1319-1334.

3. www.parkrun.org.uk 